\title{
Team for Assessment of Psychiatric Services 12th Annual Conference
}

\author{
Hugh Freeman
}

The Team for Assessment of Psychiatric Services (TAPS), which has been monitoring the process of closure of two mental hospitals, held its 12th annual conference in London on 16 July 1997. In addition to new information on the progress of cohorts of resettled ex-patients, the programme included lectures on general aspects of community psychiatry and accounts of service innovations from several counties.

Professor Norman Sartorius, President of the World Psychiatric Association, spoke of initiatives which are being undertaken by the WPA to reduce the stigmatisation of mentally ill people. He felt this was the most difficult of the challenges which are currently being made to psychiatry. The other important ones are burnout of staff and gaps between sectors of care, professional disciplines, and schools of thought. As a result, we do not speak with one voice to governments, the media, etc.

The harmful effects of stigma are not limited to patients; staff, institutions, treatment methods, families and communities or places may all be affected, sometimes for generations. Though the stigma of mental illness is present in most societies, the stigmatising features vary between cultures, as do the consequences of stigma. However, some cultural rituals can help to combat stigma, e.g. by transferring responsibility from an individual to an external agency, such as evil spirits. The mentally ill are commonly considered to be violent, unpredictable, dangerous, unable to work, producing abnormal children, etc. In addition, different stigmatised groups overlap - the sick, the bad, and the mad'. There is misrepresentation by the media. in which anti-heroes are often mentally ill, as are many violent characters on television.

Professor Sartorius listed a number of factors which have caused intolerance to grow: (i) urbanisation: (ii) increasing complexity of work; (iii) misrepresentation in the media; (iv) the fact that some mentally ill people appear strange; (v) educational inflation, whereby every hurdle provides another opportunity for people to fail; (vi) tolerance for the elderly is better where they are either few or very numerous, but not of intermediate number. Since stigma makes discrimination possible and so causes a vicious circle of disadvantage, the destigmatisation of role malfunctioning is very necessary.

If priority were given to combating stigma, there would need to be large investment in activities aimed at changing attitudes. In fact, spending on health education is $1 / 20$ of that by the motor industry on advertising. The provision of care for mental illness through general health services is an important factor, and changes in the undergraduate curriculum of the health professions are also needed. Patients and their families could also be involved in identifying discriminatory practices. Conceptual changes need to include the following: that diseases are not continuous; that a little illness is acceptable; that nobody behaves well all the time; that disablements have mental, physical and social aspects. Specific actions which Professor Sartorius recommended included school health programmes, sustained media series, emphasising the valuation of human differences and cognitive restructuring in small groups.

Professor Richard Warner from the Mental Health Center of Boulder County, Colorado, USA said that since "full employment" has come to mean $5 \%$ unemployment, there have been few opportunities for the disabled. When comparisons were made between Boulder and Italy, far more mentally ill people in Bologna were employed for more than three months and for more than $\mathbf{3 0}$ hours a week. In Trieste, a hotel is run as a workers' cooperative by psychiatric patients, with $50 \%$ of the employees being disabled. Good quality furniture is produced by patients of a drug rehabiitation programme. However, in Boulder, a financial gain compared with benefits can only be obtained if a person is working fulltime, yet unearned income decreases the likelihood of working. Disincentives to employment in the social disability system therefore need to be overcome. Compared with affective disorder. schizophrenia reduces the likelihood of working by a further $20 \%$. 
Professor Julian Leff, Director of the TAPS Project, said that Claybury Hospital had closed at the beginning of 1997, after Friern Hospital had closed in 1995. In studying the outcome of resettled patients. 1985 was taken as the point of separation between old long-stay and new longstay (who made up one-third of the total). Present State Examination (PSE) scores were an important part of the outcome variable.

So far as negative symptoms are concerned, of 531 patients seen at the baseline of the study, 317 were examined at the five-year follow-up. Between these points, the mean reduction in these symptoms was very small, although there was much variation between patients. The most important factor for explaining any aspect of outcome was the level of that feature when the individual was in hospital; those who started with no negative symptoms gained them over time, while those who started with a high level of symptoms lost some. The two factors which explained changes in the total score were, first, the score as an in-patient, and second age, with older patients showing more improvement in their mental state over five years. However, compared with younger patients, they show less increase in friends, confidants, community skills, and domestic skills.

Environmental measures showed that on the whole, rules and regulations were dramatically reduced after discharge, compared with hospital. However, private residential homes are more restrictive than public ones and the larger the household size, the more restrictive the regime. Staffed homes were associated with less increase in freedom and a greater reduction in social behaviour problems. Patients moving to smaller homes will generally have much more restricted social opportunities. Having more friends is associated with greater increase in freedom and greater reduction in social behaviour problems. Recently, for economic reasons, there has been a tendency for residential homes to get bigger. This means that they will tend to become more restrictive, yet freedom is one of the things that patients want most. Professor Leff pointed out that most staff in the residential units are untrained and unqualified, so that training is an urgent need for them.

Professor Martin Knapp said that between 1983 and 1996, the proportion of all psychiatric beds that were in hospitals had fallen from 91 to $44 \%$. Most of the decline has been since 1991 and has been in long-stay beds.

With the discharged cohorts from Friern Hospital, 92 patients were in National Health Service (NHS) community facilities, costing $£ 740$ a week; 79 were in local authority social services homes ( $£ 595$ weekly): 156 were in voluntary homes ( $\$ 663$ weekly): and 52 were in private homes (£371). Though the private homes may contain the least ill residents. differences between the characteristics of residents do not adequately explain the differences in costs. The group as a whole is quite an old one, with most residents aged between 56-61. Much of the subsequent change occurs in the first year after discharge.

Quality of care was assessed by three criteria: (i) environmental index of restrictiveness; (ii) opportunities for everyday living: (iii) social networks. On this basis, the hierarchy of quality was (i) private (worst); (ii) local authority (iii) NHS-voluntary consortium; and (iv) NHS (best). However, in the past few years, reliance on independent providers has grown; NHS funding of the total residential provision has fallen from 56 to $43 \%$. The commissioning of facilities should be based on their quality and costeffectiveness, not on the sector from which they come.

Dr Philip Thomas of the University of Bradford emphasised the importance of social factors: in London, the most socially deprived district had accumulated patients with severe mental illness at four times the rate of the least deprived area. Yet the relationship between the individual and society had been redefined by the New Right, and the legitimacy of the state as instrument of social welfare had been questioned. J. K. Galbraith had defined the 'functional underclass', found particularly in inner cities, in poor farming communities, and in rundown ex-industrial areas. These were now a permanent feature of society. and family disintegration was common among them. A Rowntree Foundation report had shown that in Britain, the poorest $20 \%$ had failed to benefit from the growing prosperity of the rest of the population.

Since developments in neuroscience hold out the prospect of understanding schizophrenia in terms of disordered individual function, poor outcome in terms of unemployment, social deterioration, poverty, and homelessness would now require to be understood within a social context. Social, interpersonal, political and cultural factors play little or no part in individual understanding, which must, therefore, be limited.

Among the many other contributions, Dr Ashley Robin and Professor Steven Hirsch reported a continuous fall in the number of compulsory admissions in England from 1965 to 1979 , but then a reversal of this trend up to 1995 , by which time the number had tripled. The number of patients occupying psychiatric beds fell throughout this period. In 1962, Tooth and Brooke had predicted that a balance would be reached with 1710 occupied beds per million population. In fact, the change to an increase in compulsory admissions was coincidental with the fall in bed numbers below 1710 per million. 
and the subsequent further reduction in beds has been associated with a steady rise in compulsory admissions.

Economic analysis of the TAPS data showed that costs have risen with successive cohorts. Many of the people who left hospital in the earlier stages were able to live relatively independently, but the greater needs of the later leavers meant that care had become more expensive to provide. The provision of care for the people discharged over the last year of the reprovision programme. including those who could not be placed in community facilities ('difficult to place' cases). was particularly costly and had a major bearing on the overall costs of the programme. The costs of community care had now become slightly, but significantly more expensive than hospital care, which was against early predictions.

Hugh Freeman, Honorary Visiting Fellow, Green College, Oxford

\section{Prevention of Anxiety and Depression in Vulnerable Groups}

\section{Joanna Murray}

The scope of this review, commissioned by the Department of Health, is the common mental disorders of anxiety and depression occurring in adults in the community. It considers the possibilities for prevention in primary care. This combination of basic conceptual and research information provides a practical framework of preventive strategies for the primary care team. Social factors in aetiology are examined in detail, and epidemiological data is used to consider vulnerability factors and to identify high risk groups. There is also a thorough review of risk for common mental disorders.

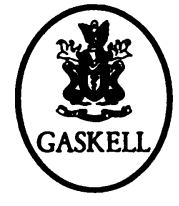

\section{$\bullet £ 7.50 \bullet 112 p p . \bullet 1995 \bullet$ ISBN 0902241877}

Available from bookshops and from the Publications Department, Royal College of Psychiatrists, 17 Belgrave Square, London SW1X 8PG (Tel. 0171-235 2351 extension 146) 